\title{
Assessing flash flood vulnerability using a multi-vulnerability approach
}

\author{
Konstantinos Karagiorgos ${ }^{1, a}$, Thomas Thaler $^{1}$, Fotis Maris ${ }^{2}$, and Sven Fuchs ${ }^{1}$ \\ ${ }^{1}$ Institute of Mountain Risk Engineering, University of Natural Resources and Life Sciences, 1190 Vienna, Austria \\ ${ }^{2}$ Department of Forestry and Management of the Environment and Natural Resources, Democritus University of Thrace, \\ 68200Orestiada, Greece
}

\begin{abstract}
In the framework of flood risk assessment, while the understanding of hazard and exposure has significantly improved over the last years, knowledge on vulnerability remains one of the challenges. Current approaches in vulnerability research are characterised by a division between social scientists and natural scientists. In order to close this gap, we present an approach that combines information on physical and social vulnerability in order to merge information on the susceptibility of elements at risk and society. With respect to physical vulnerability, the study is based on local-scale vulnerability models using nonlinear regression approaches. Modified Weibull distributions were fit to the data in order to represent the relationship between process magnitude and degree of loss. With respect to social vulnerability we conducted a door-to-door survey which resulted in particular insights on flood risk awareness and resilience strategies of exposed communities. In general, both physical and social vulnerability were low in comparison with other European studies, which may result from (a) specific building regulations in the four Mediterranean test sites as well as general design principles leading to low structural susceptibility of elements at risk, and (b) relatively low social vulnerability of citizens exposed. As a result it is shown that a combination of different perspectives of vulnerability will lead to a better understanding of exposure and capacities in flood risk management.
\end{abstract}

${ }^{\mathrm{a}}$ Corresponding author: kkaragio@boku.ac.at 


\section{Introduction}

In Europe, flooding is one of the most severe hazards repeatedly causing loss of lives and economic assets [1]. Apart from large-scale river flooding, flooding caused by heavy rainfall in small and often mountainous catchments results in adverse effects and may increase due to the continued socio-economic development in some regions [2] and the possible influence of climate change on the frequency and magnitude of hydrological processes [3, 4]. Focusing on these types of floods, the societal impact on the affected communities is dependent on land use and demographic characteristics, the quantity and quality of the elements at risk, as well as the effectiveness of mitigation provided [5, 6]. Flash flood events, defined as temporally and spatially localised, fast-evolving surface water responses to rainfall from intense thunderstorms, play an important role in Mediterranean countries and dominate the ongoing management decisions in many countries [7, 8]. Flash floods have a considerable potential for damage due to high flow velocities and thus high hazard intensities and regularly originate from small catchment where the local geology is characterised by loose sediments available for erosion or remobilisation[9]. As reported by Llasat et al.[10] the spatial distribution of flood events in Mediterranean countries has shown that an urbanised environment considerably influences the vulnerability to flood risks. In consequence, an interdisciplinary approach is encouraged to analyse the impact and response to flash flood events $[11,12]$.

While the understanding of hazard and exposure has significantly improved over the last years, knowledge on vulnerability remains one of the challenges in the management of flood risk [13], which requires the assessment of exposure [14-16]. Vulnerability is conceptualised quite differently in various scientific disciplines, and hence, it is embedded in multiple disciplinary theories underpinning either a technical or a social origin of the concept and resulting in a range of paradigms for either a qualitative or quantitative assessment [17]. Social scientists tend to view vulnerability as representing a set of socio-economic factors that determine the ability of society to cope with stress, anticipate changes or recover from the impact of hazards [18, 19]. Alternatively, natural scientists often view vulnerability in terms of the degree of loss of an element at risk as a result of the hazard impact [e.g., 20, 21].

Here, we present an approach that combines information on physical and social vulnerability in order to merge information on the susceptibility of elements at risk and of society. The main aim is to contribute to the disciplinary gap in vulnerability research by using data from four well-documented flash flood events in Greece which damaged residential buildings and commercial properties. The study has been carried out in the region of East Attica located east of Athens, and including the municipalities of Oropos and Nea Makri in the North and the municipalities of Rafina and Marathonas southern. The region of East Attica is characterised by counterurbanization due to the neighbouring capital, and substantial new infrastructure development resulting in structural changes of the communities from semi-rural to semi-urban [22]. In combination with the specific geographical settings this region repeatedly experienced hazardous flash flood events in the past [23-25, 6].

\section{Method}

\subsection{Assessment of physical vulnerability}

Physical vulnerability assessment implies the identification of the susceptibility of elements at risk and is usually defined as the impact of hazardous events on physical structures. Following this axiom, vulnerability can be expressed as a function between the degree of loss or damage ratio and the corresponding process intensity causing this loss [26-28]. Within this study, the damage ratio was computed using an economic approach by establishing a ratio between the empirically collected loss and the value of every individual element at risk [26].

The analysis was based on the evaluation of loss assessment reports; these were made just after an event and are regularly used by the governmental administration for loss compensation purposes. The data was made available by the Prefecture of East Attica. In the test sites, a total of 114 residential buildings and a total of 61 commercial properties (micro-sized enterprises) was identified as having suffered from losses.

While for the building envelope the necessary quantitative values were calculated using data provided by the Earthquake Recovery Service of Greece [29], damage referring to the household contents in the category of residential buildings was calculated using the respective legal amendment [30]. Damages referring to the contents of the commercial sector have been reported in quantitative values in the loss assessment reports. A detailed description of the method, data processing and the curve fitting procedure can be found in [31].

\subsection{Assessment of social vulnerability}

Social vulnerability can be defined as specific social inequalities in the context of a disaster [32]. In hazard research, approaches to assess social vulnerability are commonly based on indicators or indices. Consequently, we identified a total of 18 variables based on a literature review [33-36]. The variables were mainly focused on the aspect of (1) social networks with respect to length of residency, solidarity in the area, trust to people and membership in local associations or local social networks [37,38]; (2) post-incident outcomes, such as damages and psychological effects [35,39]; (3) security with respect to the village, owned properties and individual life [40,41] and (4) socio-economic and demographic characteristics, such as employment rate, educational background, age, household incomes and savings [13, 35, 39-41].The total number of respondents was 114 flood victims spread between four different villages in the study area, see Table 1. 


\begin{tabular}{lcccc}
\hline \multirow{2}{*}{ Community } & N & Mean age & \multicolumn{2}{c}{ Gender } \\
& & & Male & Female \\
\hline Nea Makri & 24 & 39.6 & $51.35 \%$ & $48.65 \%$ \\
Oropos & 42 & 44 & $55.81 \%$ & $44.19 \%$ \\
Rafina-Pikermi & 25 & 35.3 & $45.95 \%$ & $54.05 \%$ \\
Marathonas & 23 & 38.4 & $53.85 \%$ & $46.15 \%$ \\
\hline
\end{tabular}

Table 1. Characteristics of the interviewees.

The variables described above were standardised using Eqn. (1), where $\mathrm{x}^{\prime}$ is the standardized value and $\mathrm{x}$ is the observed value for which the standardized value was calculated. Min and max refer to minimum and maximum values of the scale of the variables used. A detailed description of the survey, data and development of the indicators is published in Karagiorgos et al. [31]. The categories were further summed up (by taking a simple average) using an equal weighted scheme in order to create an aggregated social vulnerability index. Higher scores indicate higher social vulnerability.

$$
\mathrm{x}^{\prime}=(\mathrm{x}-\min ) /(\max -\min )
$$

\subsection{Integrated vulnerability assessment}

In order to achieve an integrated vulnerability value, physical vulnerability $(\mathrm{PhV})$ and social vulnerability (SoV) were combined to an integrated vulnerability index (IVA) by using Eqn. 2. By doing so, both values were given equal weight because of lack of empirical data [31], neglecting any further discussion on the relative importance of one factor over the other.

$$
\mathrm{IVA}=0.5 \mathrm{PhV}+0.5 \mathrm{SoV}
$$

\section{Results}

In the following section, details on the results of physical and social vulnerability assessment as well as the combined assessment are presented.

\subsection{Physical vulnerability}

As presented in Table 2 a total of 114 residential buildings suffered losses; 64 of them not having a cellar. The total damage amounted to $€ 307,884$ with a mean damage of $€ 4,810$ per property ranging from $€ 1,174$ to $€ 10,533$. The mean degree of loss was 0.052 ranging from 0.011 to 0.321. Accordingly, for the buildings having a cellar the total damage amounted to $€ 210,410$ with a mean damage of $€ 4,208$ per property ranging from $€ 2,113$ to $€ 7,553$. The mean degree of loss was 0.025 ranging from 0.006 to 0.079 . With respect to the commercial properties, the total damage amounted to $€ 1,031,451$ with a mean damage of $€ 16,909$ per property ranging from $€ 200$ to $€ 181,256$. The mean degree of loss was 0.08 ranging from 0.001 to 0.43 .

\begin{tabular}{lcccc}
$\begin{array}{l}\text { Vulnerability } \\
\text { Building type }\end{array}$ & $\mathrm{N}$ & Loss $[€]$ & Range & Mean \\
\hline $\begin{array}{l}\text { Residential } \\
\text { with cellar }\end{array}$ & 64 & 307,884 & $0.011-0.321$ & 0.052 \\
$\begin{array}{l}\text { Residential } \\
\text { without cellar }\end{array}$ & 50 & 210,410 & $0.006-0.079$ & 0.025 \\
Commercial & 61 & $1,031,451$ & $0.001-0.43$ & 0.08 \\
\hline
\end{tabular}

Table 2.Number of buildings analysed, reported loss, vulnerability range, and mean vulnerability.

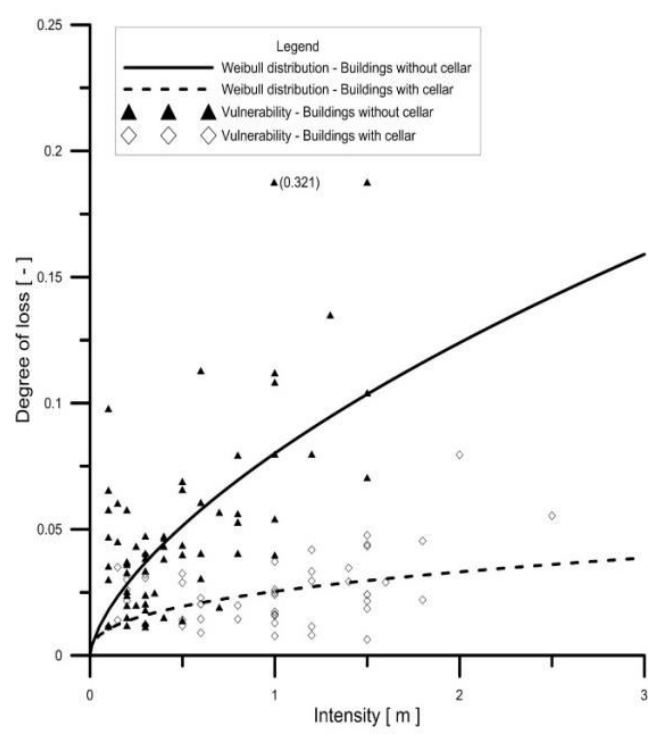

Figure 1.Vulnerability relations for residential buildings with and without a cellar based on absolute flash flood intensities. The black triangles show data for the vulnerability of buildings without cellar, the white rhombi show the data for the vulnerability of buildings with cellar. The solid line represents the Weibull distribution for the buildings without cellar, and the dashed line represents the Weibull distribution for the buildings with cellar [31].

In Figure 1, fitted Weibull functions (see Totschnig et al. [28] and Karagiorgos et al. [31, 50] for a further discussion about Weibull functions) are shown for vulnerability for residential buildings with and without cellar and based on flash flood intensities. The hazard intensity is plotted on the abscissa and grouped in steps of 0.5 metres, and the degree of loss is plotted on the ordinate. For the buildings without a cellar the results suggest a relatively sharp increase in vulnerability until a flood height of $0.5 \mathrm{~m}$, and a successively flattening curve for higher process intensities. Similarly, for the buildings with cellar, a gradual flattening is traceable once the process intensity becomes higher.

In Figure 2, the vulnerability for the category of commercial buildings is shown. As defined by the Weibull function, vulnerability is strictly increasing. For process intensities from 0 to $0.2 \mathrm{~m}$ the degree of loss is zero and therefore vulnerability equals zero. For process intensities $>0.5 \mathrm{~m}$ the degree of loss and therefore vulnerability is strictly increasing until a value of 0.468 for a water depth of $1.5 \mathrm{~m}$. 


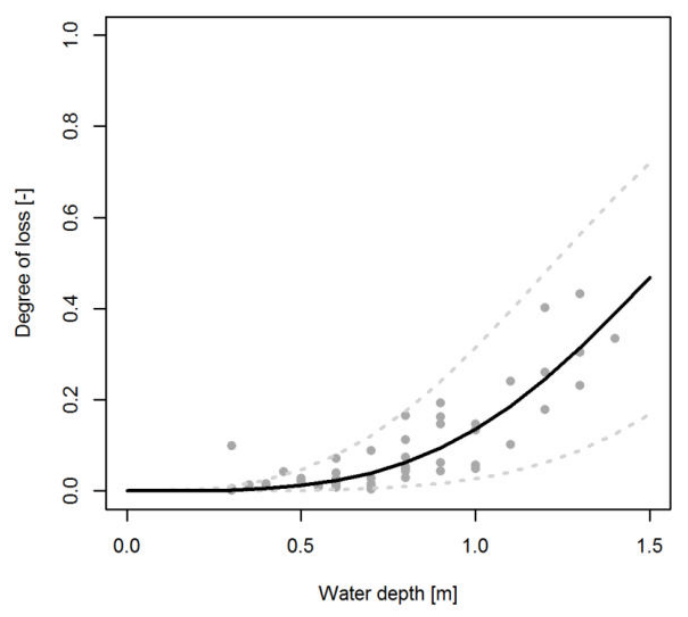

Figure 2.Vulnerability relations for commercial buildings based on absolute flash flood intensities. The black triangles show data for the vulnerability. The solid line represents the Weibull distribution for the commercial buildings [31].

\subsection{Social vulnerability}

The assessment of social vulnerability resulted in particular insights in social network, post-incident, security and socio-economic as well as demographic indicators. In order to obtain an integrated vulnerability index all these social vulnerability values were minimummaximum transformed.

The sampling generally showed a low degree of local integration or embeddedness in the region. The mean vulnerability value of social network indicators calculated equal to 0.520 . The lack of local embeddedness was represented by a low degree of solidarity/trust in people living in the village and no high interest in participation in local associations. With respect to post-incident indicators, the mean vulnerability calculated equal to 0.369 . The respondents rated the seriousness of the effects of the impact of the last flood events as insignificant. On the other hand, responders rated the seriousness of the psychological health and stress as significant factor. Focusing on security indicators, the mean vulnerability score is equal to 0.373 . The sample showed a high degree of concerns for the village, in contrast to the results for individual life and their property. Additionally, we asked responders about their flood experiences before the events. The sample showed that people were not prepared for the events. However, the minority of the responders believes that it will not face similar events in the future. Socioeconomic and demographic indicators are an important factor influencing the construction and assessment of social vulnerability in the region. The mean vulnerability value calculated equal to 0.387 . In general, the respondents showed high length of residency and disabled or non-selfsufficient persons played no role in the responds. The indicator, ownership structure, showed a high degree of private properties within the respondents. Moreover, the questionnaires showed that the household income is insufficient to satisfy the family's needs.
Finally, in order to obtain an aggregated index, social vulnerability produced out of the four different indicators equalled to 0.384 .

\subsection{Combination of physical and social vulnerability}

In order to obtain an integrated index, physical vulnerability $(\mathrm{PhV})$ based on an economic approach calculated equal to 0.041 . Similarly, the social vulnerability (SoV) produced out of four different indicators is 0.384. Based on Eqn. 2, an overall vulnerability of 0.212 was obtained for the study area.

\section{Discussion and conclusion}

In order to assess the vulnerability to flash floods in a Greek test site we presented a method of combining information on physical vulnerability and social vulnerability into one number. The applied method included a physical vulnerability assessment using an economic approach by establishing a ratio between empirically collected loss data and the value of every individual element at risk, and a social vulnerability assessment using means of indicators based on empirical data out of a door-to-door survey following flash flood events. Clearly, this approach can potentially provide a better understanding of perceptions of actors regarding their vulnerabilities and capacities.

The assessment of physical vulnerability was separately undertaken for residential and commercial buildings exposed. The results showed that while for both building categories modified Weibull functions may be used to mirror vulnerability, there were strong differences in the degree of loss between the two building categories. The differences between residential and commercial properties are due to a legally upper limit of compensation for damaged household contents in contrast to the absolute damage values used for the assessment of content in commercial properties. Because of this methodological limitation, individual vulnerability functions for residential and commercial buildings are proposed. The proposed vulnerability functions may be used in operational risk analysis for flash flood hazards in Greece as well as in other Mediterranean countries facing similar events. The resulting curves can provide an important tool for decision makers providing detail information with respect to the assessment of economic losses for future events or for different development settings.

For residential buildings the results were surprisingly low compared to other studies available in the literature, i.e. with respect to mountain regions $[4,26]$ but also with respect to flood hazards along the larger European rivers [42, 43]. Studies presented by Fuchs et al. [26] and Totschnig and Fuchs [4] focused on fluvial sediment transport and debris flow processes in mountain rivers with considerably different process characteristics than the flash flood events analysed in this paper. In contrast, the FLEMOps model presented by Kreibich et al. [43] computes a considerable part of the loss as result of the 
flood duration apart from the water depth inside the building. Moreover, low vulnerability values may be a general result from local building construction techniques as well as construction materials used, such as reinforced concrete for the construction of the supporting structures and bricks for the construction of the walls. This is in accordance with conclusions in Fuchs et al. [44] and Highfield et al. [45].

The resulting curve for commercial buildings is in line with the results presented by Kreibich et al. [46] with respect to river flooding as well as with the results presented by Papathoma-Köhle et al. [47] with respect to torrential flooding. The only difference is the smaller damage range reported within this study which can be explained by the homogeneous data set resulting from the loss analysis for micro-sized enterprises. Kreibich et al. [46] analysed small, medium and large companies and Papathoma-Köhle et al. [47] analysed tourist accommodation.

Focusing on the analysis of the buildings with and without a cellar a contradiction in the degree of loss was observed. Buildings without a cellar turned out to be more susceptible than the buildings with a cellar. Reasons why the reported degree of loss for the buildings without a cellar is more than double the loss of buildings with a cellar could be explained by the building design as well as by the building use. With respect to the building design, a significant number of the cellars was just used as car garage with no further value accumulation. On the other hand, with respect to the building use, a considerable amount of buildings is only used during summer months, which may result in reduced exposure compared to a year-round utilisation of the buildings.

Focusing on social vulnerability the results indicate that the inclusion of social network, post-incident, security and socio-economic as well as demographic indicators in an extended model for the quantification of vulnerability was useful to obtain insights on the flash flood vulnerability of households. The social vulnerability of the area can be characterised as moderate. Low degree of local integration or embeddedness in the region can be explained by socio-economic characteristics of the villages as a result of new infrastructure development, which is accountable for changing the structure of the communities from semirural to semi-urban. Moreover, East Attica is influenced by urban sprawl and respective satellite settlements from the agglomeration of Athens [48]. With respect to security indicators, analysis included variables describing flood risk perception. The area generally showed a high risk perception due to the recent flood history. Further impacts of the last flood events were reported as insignificant which mirrors the low physical vulnerability of the area. On the other hand, psychological health and stress was a significant factor for the area. It can be expected that stress and psychological problems are a result of the flash flood characteristics experienced. As reported by Terti et al.[49], flash flood events are generally very localized in space and time, and can difficultly be forecasted with precision, which subsequently leaves people uninformed and exposed to surprise in their daily activities. Analysing security indicators the sample showed a high degree of concern for the village, in contrast to the results for individual life and their property. Moreover, the majority of the interviewees agreed that future flash flood events will happen again. However, this high risk perception could not increase the preparedness in the community as a result of low individual preparedness which can have a negative impact in the warning, mitigation and recovery phase in future flash flood events.

Based on these limitations, there is a need for further research on flash flood losses in order to increase the amount of data on physical vulnerability to improve the significance of the models. Moreover, the validation of the models suggested testing the wider applicability in areas facing similar processes and building characteristics such as Spain, Italy, Portugal and southern France. Additionally, for the commercial vulnerability function, future research should focus on higher process intensities in order to improve the model. Social vulnerability limitations addressed a limited prediction of future vulnerabilities in our model. So far, future demographic, economy and social changes are not taken into account and future research is needed in order to address these impacts on the society.

To conclude, the applied method included an assessment of physical vulnerability focusing on residential and commercial properties and an assessment of social vulnerability for flash flood-prone areas in a Mediterranean environment. The results may be valuable for operational flood risk mitigation and the necessary societal adaptation.

\section{References}

1. Barredo, J., Major flood disasters in Europe: 1950-2005. Natural Hazards, 2007. 42(1): p. 125-148.

2. Fuchs, S., M. Keiler, and A. Zischg, A spatiotemporal multi-hazard exposure assessment based on property data. Natural Hazards and Earth System Sciences, 2015. 15(9): p. 2127-2142.

3. Keiler, M., J. Knight, and S. Harrison, Climate change and geomorphological hazards in the eastern European Alps. Philosophical Transactions of the Royal Society of London. Series A: Mathematical, Physical and Engineering Sciences, 2010. 368: p. 2461-2479.

4. Totschnig, R. and S. Fuchs, Mountain torrents: quantifying vulnerability and assessing uncertainties. Engineering Geology, 2013. 155: p. 31-44.

5. Tsakiris, G., Flood risk assessment: Concepts, modelling, applications. Natural Hazards and Earth System Sciences, 2014. 14(5): p. 13611369.

6. Papagiannaki, K., et al., Flash flood occurrence and relation to the rainfall hazard in a highly 
urbanized area. Nat. Hazards Earth Syst. Sci., 2015. 15(8): p. 1859-1871.

7. Gaume, E., et al., A compilation of data on European flash floods. Journal of Hydrology, 2009. 367(1-2): p. 70-78.

8. Marchi, L., et al., Characterisation of selected extreme flash floods in Europe and implications for flood risk management. Journal of Hydrology, 2010. 394(1-2): p. 118-133.

9. Hong, Y., P. Adhikari, and J.J. Gourley, Flash flood, in Encyclopedia of Nat. Hazards, P.B. (Ed.), Editor 2012, Springer.

10. Llasat, M., et al., High-impact floods and flash floods in Mediterranean countries: the FLASH preliminary database. Advances in Geosciences, 2010. 23: p. 47-55.

11. Gruntfest, E., et al., Dealing with Flash Floods: Contemporary Issues and Future Possibilities, in Coping With Flash Floods2001, Springer Netherlands. p. 3-10.

12. Špitalar, M., et al., Analysis of flash flood parameters and human impacts in the US from 2006 to 2012. Journal of Hydrology, 2014. 519, Part A(0): p. 863-870.

13. Koks, E.E., et al., Combining hazard, exposure and social vulnerability to provide lessons for flood risk management. Environmental Science and Policy, 2015. 47: p. 42-52.

14. Fuchs, S., J. Birkmann, and T. Glade, Vulnerability assessment in natural hazard and risk analysis: current approaches and future challenges. Natural Hazards, 2012. 64(3): p. 1969-1975.

15. Meyer, V., et al., Review article: Assessing the costs of natural hazards - state of the art and knowledge gaps. Natural Hazards and Earth System Sciences, 2013. 13(5): p. 1351-1373.

16. Rojas, R., L. Feyen, and P. Watkiss, Climate change and river floods in the European Union: Socio-economic consequences and the costs and benefits of adaptation. Global Environmental Change, 2013. 23(6): p. 1737-1751.

17. Fuchs, S., Susceptibility versus resilience to mountain hazards in Austria - Paradigms of vulnerability revisited. Natural Hazards and Earth System Sciences, 2009. 9(2): p. 337-352.

18. Birkmann, J., ed. Measuring vulnerability to natural hazards. 2006, United Nations University Press: Tokyo. 524.

19. Field, C.B., et al., eds. Climate Change 2014: Impacts, adaptation, and vulnerability. 2014, Cambridge University Press: Cambridge. 1132.

20. Fell, R., et al., Guidelines for landslide susceptibility, hazard and risk zoning for landuse planning. Engineering Geology, 2008. 102(3-4): p. 85-98.

21. Papathoma-Köhle, M., et al., Improvement of vulnerability curves using data from extreme events: debris flow event in South Tyrol. Natural Hazards, 2012. 64(3): p. 2083-2105.
22. Theodoropoulou, H., M. Vamvakari, and R. Mitoula, Community development in the east prefecture of attica, greece, following the 2004 summer olympic games of Athens. International Journal of Sustainable Development and Planning, 2009. 4(2): p. 112.

23. Diakakis, M., A method for flood hazard mapping based on basin morphometry: application in two catchments in Greece. Natural Hazards, 2010. 56(3): p. 803-814.

24. Lasda, O., A. Dikou, and E. Papapanagiotou, Flash flooding in Attica, Greece: climate change or urbanization? AMBIO: A Journal of the Human Environment, 2010. 39: p. 608-611.

25. Papagiannaki, K., K. Lagouvardos, and V. Kotroni, A database of high-impact weather events in Greece: A descriptive impact analysis for the period 2001-2011. Natural Hazards and Earth System Science, 2013. 13(3): p. 727.

26. Fuchs, S., K. Heiss, and J. Hübl, Towards an empirical vulnerability function for use in debris flow risk assessment. Natural Hazards and Earth System Sciences, 2007. 7(5): p. 495-506.

27. Fuchs, S., C. Kuhlicke, and V. Meyer, Editorial for the special issue: vulnerability to natural hazards - the challenge of integration. Natural Hazards, 2011. 58(2): p. 609-619.

28. Totschnig, R., W. Sedlacek, and S. Fuchs, A quantitative vulnerability function for fluvial sediment transport. Natural Hazards, 2011. 58(2): p. 681-703.

29. Greek Ministry of Infrastructure, T.a.N., Invoice for the calculation of necessary repair works in buildings affected by natural hazards (earthquake, forest fires, floods, landslides) and the respective housing assistance, O.G.B.I. Greek). Editor 2011.

30. Solidarity, G.M.f.H.a.S., Specifications for the calculation of the financial support for people affected by natural hazards, O.G.B.I.G. Joint Ministerial Decision 2673/29.8.2001, Editor 2001.

31. Karagiorgos, K., et al., Integrated flash flood vulnerability assessment: insights from East Attica, Greece. Journal of Hydrology, in press.

32. O'Keefe, P., K. Westgate, and B. Wisner, Taking the naturalness out of natural disasters. Nature, 1976. 260(5552): p. 566-567.

33. Tapsell, S., et al., Vulnerability to flooding: health and social dimensions. Philosophical Transactions of the Royal Society of London. Series A: Mathematical, Physical and Engineering Sciences, 2002. 360(1796): p. 1511-1525.

34. Cutter, S., B. Boruff, and W. Shirley, Social vulnerability to environmental hazards. Social Science Quarterly, 2003. 84(2): p. 242-261.

35. Fekete, A., Validation of a social vulnerability index in context to river-floods in Germany. Natural Hazards and Earth System Sciences, 2009. 9(2): p. 393-403. 
36. Felsenstein, D. and M. Lichter, Social and economic vulnerability of coastal communities to sea-level rise and extreme flooding. Natural Hazards, 2014. 747(1): p. 463-491.

37. Hurlbert, J.S., V.A. Haives, and J.J. Beggs, Core networks and tie activation: what kinds of routine networks allocate resources in nonroutine situations? Am. Sociol. Rev. , 2000. 65: p. 598-618.

38. Kuhlicke, C., et al., Perspectives on social capacity building for natural hazards: outlining an emerging field of research and practice in Europe. Environmental Science \& Policy, 2011. 14(7): p. 804-814.

39. Kuhlicke, C., et al., Contextualizing social vulnerability: findings from case studies across Europe. Natural Hazards, 2011. 58(2): p. 789810.

40. Cutter, S.L., Vulnerability to environmental hazards. Progress in Human Geography, 1996. 20(4): p. 529-539.

41. Cutter, S.L., The vulnerability of science and the science of vulnerability. Annals of the Association of American Geographers, 2003. 93(1): p. 1-12.

42. Apel, H., et al., Flood risk analyses - How detailed do we need to be? . Natural Hazards, 2009. 49(1): p. 79-98.

43. Kreibich, H., et al., Is flow velocity a significant parameter in flood damage modelling? Natural Hazards and Earth System Sciences, 2009. 9(5): p. 1679-1692.

44. Fuchs, S., M. Holub, and J. Suda, Reducing physical vulnerability to mountain hazards by local structural protection, in Internationales Symposion Interpraevent, G. Koboltschng, J. Hübl, and J. Braun, Editors. 2012, Internationale Forschungsgesellschaft Interpraevent: Genoble. p. 675-686.

45. Highfield, W.E., S.A. Norman, and S.D. Brody, Examinating the 100-year floodplain as a metric of risk, loss, and household adjustment. Risk Analysis, 2013. 33(2): p. 186-191.

46. Kreibich, H., et al., Development of FLEMOcs a new model for the estimation of flood losses in the commercial sector. Hydrological Sciences Journal, 2010. 55(8): p. 1302-1314.

47. Papathoma-Köhle, M., et al., Loss estimation for landslides in mountain areas - An integrated toolbox for vulnerability assessment and damage documentation. Environmental Modelling and Software, 2015. 63: p. 156-169.

48. Sapountzaki, K., et al., Disconnected policies and actors and the missing role of spatial planning throughout the risk management cycle. Natural Hazards, 2011. 59(3): p. 1445-1474.

49. Terti, G., et al., Dynamic vulnerability factors for impact-based flash flood prediction. Natural Hazards, 2015.
50. Karagiorgos, K., et al Multi-vulnerability analysis for flash flood risk management. Natural Hazards, 2016. 82(1): p. 63-87 